\title{
Competition-defense tradeoff increases the diversity of microbial plankton communities and dampens trophic cascades
}

Cadier, Mathilde; Andersen, Ken Haste; Visser, Andre ; Kiørboe, Thomas

Published in:

Oikos

Link to article, DOI:

10.1111/oik.06101

Publication date:

2019

Document Version

Peer reviewed version

Link back to DTU Orbit

Citation (APA):

Cadier, M., Andersen, K. H., Visser, A., \& Kiørboe, T. (2019). Competition-defense tradeoff increases the diversity of microbial plankton communities and dampens trophic cascades. Oikos, 128(7), 1027-1040. https://doi.org/10.1111/oik.06101

\section{General rights}

Copyright and moral rights for the publications made accessible in the public portal are retained by the authors and/or other copyright owners and it is a condition of accessing publications that users recognise and abide by the legal requirements associated with these rights.

- Users may download and print one copy of any publication from the public portal for the purpose of private study or research.

- You may not further distribute the material or use it for any profit-making activity or commercial gain

- You may freely distribute the URL identifying the publication in the public portal 
Competition-defense tradeoff increases the diversity of microbial plankton communities and dampens trophic cascades

Mathilde Cadier, Ken H. Andersen, Andre W. Visser and Thomas Kiørboe

Centre for Ocean Life, DTU Aqua, Technical Univ. of Denmark, 2800 Kgs. Lyngby, Denmark

Corresponding author: Mathilde Cadier, Centre for Ocean Life, DTU Aqua, Technical Univ. of Denmark, 2800 Kgs. Lyngby, Denmark. E-mail: mcad@aqua.dtu.dk

Decision date: 05-Feb-2019

This article has been accepted for publication and undergone full peer review but has not been through the copyediting, typesetting, pagination and proofreading process, which may lead to differences between this version and the Version of Record. Please cite this article as doi: [10.1111/oik.06101]. 


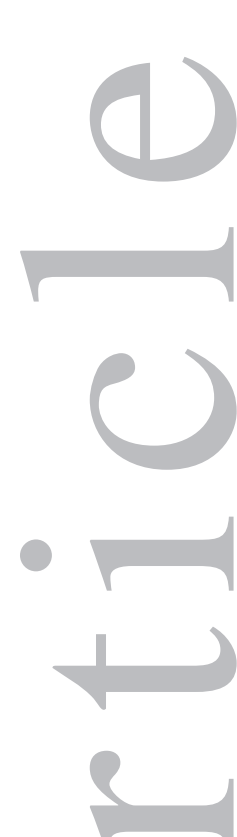

\section{Abstract}

The competition-defense tradeoff is a significant source of functional diversity in ecological communities. Here, we present a theoretical framework to describe the competition-defense tradeoff and apply it to a size-based model of a unicellular plankton community. Specifically, we investigate how the emergent community structure depends on the shape of the trade-off, and on whether the cost of defense is paid for by a lowered resource affinity or by an elevated metabolic rate. The inclusion of defense affects the size distribution and trophic strategies of the emerging community dependent on environmental conditions (eutrophic versus oligotrophic) and leads to increased diversity in size and trophic strategy under eutrophic conditions. Eutrophic conditions allow for better-defended organisms than oligotrophic conditions. In most scenarios, competition-defense tradeoffs dampen trophic cascades in the seasonal cycle simulations, and increase the abundance of mixotrophs. We further demonstrate that it matters how the cost of defense is manifest (decreased affinity vs. increased metabolic rate), and that it has a significant effect on the resulting plankton community (overall biomass, size and feeding strategy diversity), particularly when the efficiency of the defense increases in direct proportion to the investment. Our results demonstrate that the structure of the ecosystem crucially depends on details of the defense tradeoff. This finding highlights the importance of a mechanistic understanding of defense tradeoffs, e.g. obtained through experimental measurements of specific defense mechanisms.

Key-words: Unicellular plankton, food-web modeling, mixotrophy, competitiondefense tradeoff, seasonal succession, coexistence 


\section{INTRODUCTION}

Evidence is accumulating that functional diversity is essential to ecosystem functioning, such as the transfer of energy and material to higher trophic levels and the magnitude of carbon sequestration (Duffy and Stachowicz 2006). The diversity of marine phytoplankton communities typically exceeds that expected from competitive exclusion (Hutchinson 1961, Tilman 1982). This apparent 'Paradox of the Plankton' can be explained by several mechanisms, including predation (Levin 1970) and the consequent evolution of costly defense mechanisms (Kraaijeveld and Godfray 1997, Wolfe 2000). Predation is thus a significant source of diversity (Huisman et al. 2001, Scheffer et al. 2003). The enhancement of diversity, however, requires, that the defense comes at a cost, else the best defended species would outcompete less defended ones (Grover 1995). Also, the shape of the trade-off, i.e., how the benefits of defense vary with the cost of defense, has implications to the structure and function of the resulting plankton community (Boots and Haraguchi 1999, Viola et al. 2010, Våge et al. 2014).

Defense in unicellular plankton is expressed through a large variety of mechanisms, ranging from size and shape modifications to colony formation, toxin production, or stealth behavior, and these are in many cases harnessed or upregulated in the presence of predators (Pančić and Kiørboe 2018). The trade-offs are defense specific and are often not quantified (Viola et al. 2010, Boots 2011, Pančić and Kiørboe 2018). It is therefore challenging to design a universal mathematical formulation of the trade-off between defense and competitive ability. Two issues are potentially important: (i) the shape of the trade-off, i.e. how the benefits of the defense (reduced predation mortality) vary with the costs of being defended (reduced competitive ability or growth), and (ii) how the cost of the defense is 'paid' for, i.e. as reduced resource affinity or as elevated energy expenditure. 
The trade-off curve can be linear or nonlinear (Loeuille and Loreau 2004) (Fig. 1a). A linear relation implies that the benefits are proportional to the costs of the defense. A non-linear trade-off function typically implies that defense mechanism yields diminishing returns as the investment $(S)$ increases (full curved lines in Fig. 1a, hereafter termed 'cheap defense') (Våge et al. 2014).

Whether the defense costs are paid as resource allocation to defense or as reduced resource affinity (Fig. 1b) depends on the defense mechanism as well as on environmental conditions (Loeuille and Loreau 2004). For example, stealth behavior reduces the resource affinity (Kiørboe et al. 2014) and production of defense toxins may reduce the resources available for growth in protists (Brandenburg et al. 2018), but mainly when resources are limiting (Chakraborty et al. 2018).

Previous modelling exercises have demonstrated that both the shape of the trade-off (Våge et al. 2014) and how the costs are paid (Erlich and Gaedke 2018) have implications to the outcome of competition. Here, we extend the framework proposed by Våge et al. (2014) by investigating the influence of both the shape of the trade-off and the way the costs are paid for on the community structure in a size-based food web model of unicellular plankton that also considers trophic strategies (auto-, hetero- and mixotrophy) (Chakraborty et al. 2017). Size distribution, trophic strategies, defense strategies, and food web structure are all emergent properties of the model, not prescribed. The plankton community we explore is therefore more realistic and complex than the simple food webs examined by Våge et al. $(2014,2018)$ and Erlich and Gaedke (2018) (Fig. 1c), but its structure is governed by simple rules and few parameters. This additional complexity is able to resolve the effect of defense mechanisms on ecosystem dynamics in the realistic setting including more than two trophic levels. We apply the model to both oligotrophic and eutrophic conditions at steady state, and explore its behavior in a seasonal environment. We show that the diversity in terms of both size 
and trophic strategies are typically enhanced by defense, and that the structuring role on plankton communities depends on the shape of the competition/defense trade-off and on the cost formulation.

\section{METHODS}

\section{Size-based mixotrophic model}

We consider a size-structured microbial food web in the photic zone as modelled by a chemostat. The equations represent a well-mixed upper water column that exchanges nutrient $\left.N\left(\mu \mathrm{gN} \mathrm{L}^{-1}\right)\right)$ and plankton $P\left(\mu g \mathrm{~g} \mathrm{~L}^{-1}\right)$ with a deep layer at a dilution rate $\mathrm{r}\left(\mathrm{d}^{-}\right.$ $\left.{ }^{1}\right)$. Nutrient and plankton concentrations of each size class in the deep layer are denoted $\mathrm{N}_{0}$ and $\mathrm{P}_{0}$, respectively. All symbols and parameter values are given in Table 1.

Total biomass of plankton $P$ is divided in 9 discrete size classes $\left(n_{\text {size }}\right)$ each allowing autotrophy, mixotrophy or heterotrophy to emerge as a result of environmental resource concentrations and size-scaled affinities for the various resources (nutrients, light, prey) (Chakraborty et al. 2017). We consider cells with diameters ranging from 0.1 to $100 \mu \mathrm{m}$ with corresponding carbon mass $(M)$ varying between $10^{-7}$ and $10^{1} \mu \mathrm{gC}$. This carbon size range is discretized evenly on a $\log 10$ scale in $n_{\text {size }}=9$ size classes.

Each size class is further subdivided into 11 defense strategies $\left(n_{\mathrm{def}}\right)$ ranging from no defense $(S=0)$ to full defense $(S=1)$, yielding a complex food web (Fig. 1c). The governing equation of each plankton compartment of size $i$ and defense strategy $\xi$ is of the form:

$$
\begin{aligned}
\frac{d P_{i, \xi}}{d t}=r\left(P_{0}\right. & \left.-P_{i, \xi}\right) \\
& +\left(\mu_{i, \xi}-m_{p, i, \xi}-m_{\mathrm{HTL}, i, \xi}\right. \\
& \left.-m_{0, i, \xi} P_{i, \xi}\right) P_{i, \xi}
\end{aligned}
$$


The first term of Eq. 1 represents the fluxes in the upper water column and the second term the net growh rate of plankton. The net growth rate is computed using the difference between division rate $\mu$ and the losses through predation $m_{p}$ from larger mixotrophs, predation from higher trophic levels (copepods) $m_{H T L}$ and a quadratic term to represent viral lysis $m_{0}$ (Eq. 1).

The dynamics of nutrient $N$ is :

$$
\frac{d N}{d t}=r\left(N_{0}-N\right)+\sum_{i=1}^{n_{\text {size }}} \sum_{\xi=1}^{n_{\mathrm{def}}}\left(\epsilon m_{0, i, \xi} P_{i, \xi}-g_{i, \xi}\right)
$$

As for plankton variables, nutrients are exchanged between the chemostat and an external pool $\left(N_{0}\right)$ with the dilution rate $r$. A fraction $\epsilon=0.8$ of the plankton biomass exposed to viral lysis $m_{0}$ is directly remineralized to the dissolved nutrient pool while the remaining part is lost. The effective uptake of nitrogen $g$ is subtracted.

\section{Resource affinity and uptake}

Plankton growth, $\mu_{\mathrm{i}, \xi}$ derives from phototrophy and/or phagotrophy, resulting in fluxes of carbon and nitrogen into the cell. Each flux, denoted $J\left(\mu g C \mathrm{~d}^{-1}\right.$ or $\left.\mu g \mathrm{~g} \mathrm{~d}^{-1}\right)$ is described by a linear functional response of the resource availability $(X)$ :

$$
J_{X, i, \xi}=A_{X . i, \xi} X
$$

where $X$ represents either light $L\left(\mathrm{~W} \mathrm{~m}^{-2}\right)$, nitrogen $N\left(\mu \mathrm{gN} \mathrm{L}^{-1}\right)$, or food $F_{i, \xi}\left(\mu g \mathrm{~g} \mathrm{~L}^{-1}\right)$ from other organisms. For simplicity, we assume the uptake of resources to be linear, and introduce the rate limiting (i.e. saturating) effect on biosynthesis, introduced below.In Eq. 3, $A$ is the affinity for uptake, which is a function of the cell size, and of defense strategy. Only the size effect is shown here, and the implementation of defense 
is described below. In the absence of defense, the affinities for light, inorganic nitrogen and food are:

$$
A_{X, i}=c_{X} M_{i}^{\delta_{X}}
$$

where $c_{X}$ and $\delta_{X}$ determine how the affinity scales with size. These two parameters vary for the three resources: the affinity for inorganic nutrients scales with the radius of the spherical cells, $\delta_{N}=1 / 3$, whereas the affinity for light depends on the total surface, $\delta_{L}=2 / 3$, and the affinity for food depends on the volume of the cell, $\delta_{F}=1$.

$F_{i, \xi}$, the amount of food available for plankton $P_{i, \xi}$, is computed as the sum of all plankton scaled by the preference $\theta_{i, j}$ of each prey size (denoted $j$ ) for predator $i$, The availability of a given prey for a predator is reduced as the prey's investment in defense $(S)$ increases. The parameter $\tau$ defines the shape of the competition/defense trade-off (Fig. 1a):

$$
F_{i, \xi}=\sum_{j=1}^{n_{\text {size }}} \sum_{\xi=1}^{n_{\text {def }}}\left(1-S_{j, \xi}^{\tau}\right) \theta_{i, j} P_{j, \xi}
$$

Prey preference follows a predator/prey size ratio described using a log-normal function:

$$
\theta_{i, j}=\exp \left[-\frac{\left(\ln \left(\frac{M_{i}}{\beta M_{j}}\right)\right)^{2}}{2 \sigma^{2}}\right]
$$

where $\beta$ is the preferred predator-prey mass ratio and $\sigma$ the width of the size selection. Following Liebig's law, the resulting flux towards the cell $\left(J_{\mathrm{eff}, i, \xi}\right.$ in $\left.\mu \mathrm{gN} \mathrm{L}^{-1}\right)$ is the smallest of the fluxes of carbon and nitrogen adjusted by a fixed $\mathrm{C} / \mathrm{N}$ ratio $\left(c_{C N}\right)$ : 


$$
J_{\mathrm{eff}, i, \xi}=\min \left\{J_{F, i, \xi}+\frac{\max \left(0, J_{L, i, \xi}-R_{0} M_{i}\right)}{c_{C N}}, J_{N, i, \xi}+J_{F, i, \xi}\right\}
$$

where the first term accounts for the uptake of carbon and the second for the uptake of nitrogen. Respiratory losses $R_{0}$ are assumed to be proportional to the cell size. When nitrogen is in excess and growth is carbon-limited, the excess nitrogen taken up by the cell $(\eta)$ is immediately released to the nitrogen pool N. Therefore, the leakage of nitrogen by plankton of size $i$ and defense strategy $\xi$ is:

$$
\eta_{i, \xi}=\max \left(0, J_{N, i, \xi}-\frac{\max \left(0, J_{L, i, \xi}-R_{0} M_{i}\right)}{c_{C N}}\right)
$$

\section{Cell division rate}

The division rate is limited by the synthesis capacity of the cell, which is described using a type II functional response to compute the specific growth rate $\left(\mathrm{d}^{-1}\right)$ :

$$
\mu_{i, \xi}=\mu_{\max } f_{i, \xi} \text { with } f_{i, \xi}=\frac{J_{\mathrm{eff}, i, \xi}}{J_{\mathrm{eff}, i, \xi}+\mu_{\max } M_{i}}
$$

where the maximum synthesis rate $\mu_{\max }$ is independent of size.

Subsequently, the effective uptake of nitrogen rate $g$ is:

$$
g_{i, \xi}=\left(J_{N, i, \xi}-\eta_{i, \xi}\right)\left(1-f_{i, \xi}\right) \frac{P_{i, \xi}}{M_{i}} C_{C N}
$$

\section{Predation losses}

The loss to predation from larger mixotrophs $m_{p, i, \xi_{\text {prey }}}\left(\mathrm{d}^{-1}\right)$ for a plankton $i, \xi_{\text {prey }}$ is the sum of the grazing by each predator denoted $j, \xi_{\text {pred }}$ (Hartvig et al., 2011):

$$
\begin{aligned}
& m_{p, i, \xi_{\text {prey }}}= \\
& \sum_{j=1}^{n_{\text {size }}} \sum_{\xi_{\text {pred }}=1}^{n_{\text {def }}} A_{F, j, \xi_{\text {pred }}} \cdot \theta_{j, i}\left(1-f_{j, \xi_{\text {pred }}}\right) P_{j, \xi \text { pred }} \frac{C_{C N}}{M_{j}}
\end{aligned}
$$


Mortality increases with the predators' preference for the prey $(\theta)$, the abundance of the predators $(P)$, and their effective clearance rate $\left(A_{F}(1-f)\right.$, where $1-f$ represents the reduction of feeding due to satiation) (Eq. 9).

The three largest size classes are subject to predation from higher trophic levels $m_{\mathrm{HTL}}$ with the predation rate $m_{\mathrm{HTL} 0}$ increasing with prey size (Table 1$)$ and decreasing with investment in defense :

$$
m_{H T L, i, \xi}=\left(1-S_{i, \xi}^{\tau}\right) m_{\mathrm{HTL} 0, \mathrm{i}}
$$

\section{Competition-defense trade-off}

Within each size class, the eleven defense subclasses are assigned a fixed defense strategy. The defense strategy index $S$ varies between 0 (no defense) and 1 (full defense). $S$ is used to adjust both the gain of defense through decreased predation mortality (eq. 12) and the cost of defense as decreased competitive ability.

Given the uncertainty of the defense mechanisms, we explore three formulations for the cost of the defense (Table 2):

1. Reduced affinity for uptake of inorganic nutrients, $A_{N}$

2. Reduced affinities for uptake of both inorganic nutrients and prey, $A_{N}$ and $A_{F}$

3. Elevated metabolic rate to 'pay' for the defense, implemented as a decreased flux of the limiting elements (carbon and nitrogen), referred to as 'Add. cost' in figures and Table 2

Whether the penalty is in terms of reduced resource affinity or elevated metabolism, it may result in decreased growth rate, but the growth reduction depends differently on the resource concentration: when affinity is reduced, the growth reduction will diminish 
with increasing resource concentration, whereas it is concentration-independent in the case of elevated metabolism.

To implement the shape of the trade-off we follow Våge et al. (2014) by introducing a dimensionless shape factor $\tau$ where predation mortality (predator preference) is scaled by $\left(1-S^{\tau}\right)$ while the decrease of competitive ability is done by multiplying affinities by the function $(1-S)^{\tau}$. This formulation results in the gain-cost trade-off showed in Fig. 1a. The shape parameter $\tau$ is varied between 0.1-1: a value of 1 reflects the linear relationship whereas smaller values reflect 'cheap' defenses with diminishing returns and with 0.1 as the most non-linear, and cheapest defense.

\section{Numerical implementation and analysis}

The system was solved in Matlab (Version 2017a) using the ODE solver ODE45 which implements a $4^{\text {th }}$ order Runge-Kutta resolution method with an adaptive step size control (Shampire and Reichelt 1997). The model was run over a period of five years for each set of parameters (10 values of $\tau$ x 3 cost definitions +1 simulation without defense) and for two nutrient enrichment conditions. This simulation period is sufficient to achieve steady state or a repeatable seasonal cycle.

External inorganic nitrogen concentration $\left(\mathrm{N}_{0}\right)$ was 1 or $12 \mu \mathrm{molN} \mathrm{L}^{-1}$ for the oligotrophic and the eutrophic scenario, respectively. Light intensity was kept constant at $50 \mathrm{~W} \mathrm{~m}^{-2}$ in the steady-state experiments. For each simulation, we computed the Shannon-Wiener Index (Shannon, 1948) to quantify size diversity.

For each size class we also computed the mean and standard deviation of the trophic strategy (heterotrophic $\mathrm{N}$-flux to total $\mathrm{N}$ flux, $\frac{J_{F}}{J_{F}+J_{N}}$, biomass-averaged over the 11 defense subclasses) as well as the mean defense strategy. A change in defense investment does not change the relative benefits given by autotrophic versus heterotrophic strategies in formulations 2 and 3 of the cost of defense. Therefore, the 
standard deviation of the trophic strategy within a single size class is only different from zero when defense costs are paid by reduced nutrient affinity (formulation 1).

To simulate a typical seasonal cycle of a temperate ocean we varied light and dilution rate seasonally. Light followed the smoothed annual variability of the $24 \mathrm{~h}$ averaged photosynthetic available radiations computed over the mixed layer depth in a seasonally stratified region of a temperate coastal sea $\left(48^{\circ} 08^{\prime} \mathrm{N} ; 6^{\circ} 15^{\prime} \mathrm{E}\right)$ (Cadier et al. 2017) (Fig. 2). Seasonal variability in stratification is simulated by a seasonal variation in dilution rate (between $0.001 \mathrm{~d}^{-1}$ in summer and $0.1 \mathrm{~d}^{-1}$ during winter; Fig. 2). The seasonal cycle of plankton community is assessed for a simulation without defense mechanisms and for each of the three cost definitions for both $\tau=1$ (linear trade-off) and $\tau=0.1$ (cheap defense).

\section{RESULTS}

\section{Steady state}

In the simulations without defense (dashed lines in Fig. 3), when nutrients are not limiting, the unicellular plankton biomass at steady state is distributed between small autotrophs and large heterotrophs due to a trophic cascading effect (Fig. 3, left column and Fig. 4a). In oligotrophic conditions, however, the biomass distribution is fairly flat, the largest heterotrophic cells being excluded from the system due to in sufficient production. A wider size range of cells use a mixotrophic strategy and the total biomass is about 10 times lower in oligotrophic conditions compared to eutrophic conditions (Fig 4).

\section{Effect of defense on size distribution and trophic strategies}

The size structure of the plankton community is modified by the implementation of defense, but differently for the two nutrient regimes (Fig. 3). Under eutrophic conditions, adding defense substantially increases both size diversity (Fig. 5a) with a larger fraction of the biomass now in intermediate size classes (Fig. 3, left column), and 
trophic diversity now with more mixotrophy among larger cells (Fig. 4a). The cost formulation and the shape of the trade-off do not qualitatively affect the results (Fig. 3, left column and Fig. 5a).

In oligotrophic conditions (Fig. 3, right column), the main effect of defense is almost opposite of that at eutrophic conditions, in that defense decreases size diversity, unless the trade-off is linear or near linear (Fig. 5b). For small values of $\tau$ (cheap defense), the size distribution moves towards smaller, phototrophic cells compared to a scenario without defense, largely independent of the cost formulation (Fig. 3, Fig. 4b). Trophic strategies within size classes are unaffected by defense (Fig. 4b)

Optimal defense strategy: effects of the trade-off, cost formulation, and nutrient

\section{conditions}

The effect of the shape parameter $\tau$ on the optimal defense strategy depends on the cost formulation (i.e., where the costs are paid) and nutrient conditions (Fig. 6), but in general costly defenses lead to smaller investment in defense under oligotrophic conditions. Under eutrophic conditions (Fig. 6, left column), most cells in all size classes can afford being well defended (large ' $S$ ') when the defense is cheap (small $\tau$ ), and this is also the case for expensive defense (large $\tau$ ) when the defense cost materializes as reduced nutrient affinity. When the costs are paid as reduced affinity for both nutrients and food, small auto- and mixotrophic cells are still well defended, but the larger, more heterotrophic cells can no longer afford a strong defense. Finally, when the costs materialize as elevated metabolic expenditures, most cells in all size classes are poorly defended.

Under oligotrophic conditions (Fig. 6, right column) and when the defense is cheap, there is a large spread in defense strategy in all size classes, independent of the cost formulation. When the defense is expensive $(\tau=1)$, however, defense investment increases with cell size when costs are paid as reduce nutrient affinity as it applies only 
to small phototrophic cells. The reverse pattern is seen when the cost of the defense leads to reduced affinity for both nutrients and food, and cells of all sizes are poorly defended when the costs are paid as elevated metabolic requirements.

\section{Seasonal cycle}

\section{Simulation without defense}

In the absence of defense, the seasonal cycle is characterized by two distinct peaks of biomass in early spring (March to late April) and late summer (September and October) (Fig. 7a), similar to what is commonly observed in temperate seas. The two peaks have similar community compositions with dominance of small autotrophs and, at a lower concentration, large heterotrophs, and low biomass of cells with intermediate size (Fig. 7b). This is the result of a trophic cascade where the large heterotrophs graze down intermediately sized cells, hence relaxing predation on the smallest autotrophs.

\section{Effect of the competition/defense trade-off}

In general, the implementation of defense leads to increased summer plankton biomass, larger size coexistence, promotion of mixotrophy in intermediate size classes and a more pronounced temporal succession in size (Fig. 7c-n). The promotion of mixotrophy is mainly an indirect effect of intermediately sized cells becoming relatively more abundant. The model simulates in all scenarios an apparently counterintuitive negative correlation between the intensity of defense and the abundance of defended cells. However, the promotion of defense is a response to high predation pressure (May- June, Fig. 7, c-d and f-g) and a consequent low abundance of defended cells, and the defense is successful in the sense that their abundance is increased relative to the undefended situation. When defense costs are cheap $(\tau=0.1)$, the pattern that emerges is largely independent of the cost formulation (here illustrated for costs on reduced nutrient affinity only, Fig. 7c-e): small autotrophs dominate during winter and early spring, average cell size increases and becomes more diverse in the course of the spring and 
early summer with increased abundance of well-defended mixotrophs. When defense costs are high (linear trade-off), the seasonal pattern depends on the cost formulation: with defense costs paid as reduced nutrient affinity only, the pattern is qualitatively similar to that for cheap defenses described above, except that biomasses are lower. If defense costs are applied to affinities of both inorganic nutrients and food, there is a persistent high concentration of small autotrophic cells throughout the year and similarly high concentrations of large heterotrophs during summer (Fig. 7i). When the defense is paid through elevated metabolic costs, the temporal pattern is similar to that without defense, except that biomasses are much lower and the trophic cascade less pronounced (Fig. 71).

\section{DISCUSSION}

\section{Defense trade-offs and microbial community structure}

The composition of plankton assemblages emerges from the complex interplay between the environment and the organisms according to their functional traits. In natural communities, temporal variation such as seasonality drive the successions by selecting for traits that are best fitted to the prevailing environmental conditions, both physical (e.g. temperature, nutrients, light), and biotic (e.g. competition, predation, parasitism). The role of predators and grazing losses in shaping seasonal succession has long been recognized (Evans and Parslow 1985). Predators not only decrease the abundance of their prey but also influence the dynamics of the competition by changing the resource availability (Sterner 1989), selecting for well-defended prey (Lynch and Shapiro 1981), and by facilitating species coexistence through trade-offs (Chesson 1991). Indeed, the competition-defense trade-off is known to promote coexistence by the so-called killingthe-winner mechanism derived from the keystone predator concept as demonstrated by both theory (Leibold et al. 1989, Holt et al. 1994, Winter et al. 2010) and experiments with plankton communities (McCauley and Briand 1979, Leibold et al. 2017). 
While earlier theoretical studies have examined the effects of defense in simpler food web structures (e.g. 'diamond' or 'pentagon' food webs model) and in constant environments (Våge et al. 2014, 2018, Ehrlich and Gaedke 2018) we have here examined a more complex - and realistic - size based food web with multiple trophic levels and including trophic strategies. While the resulting patterns in our simulation appear much richer than those emerging in simpler models, they do in fact reproduce some of the key findings from previous studies. Defense leads to increased coexistence (diversity) in eutrophic conditions, eutrophic conditions allow the existence of better defended organisms (Våge et al. 2014, 2018), and co-existence is (slightly) more pronounced when the costs are in terms of reduced affinities rather than reduced growth (Ehrlich and Gaedke 2018). In addition to the increase in diversity along the competition-defense dimension as explored by the simpler models, we here also find changes in diversity in sizes as well as in trophic strategies (i.e. auto-, hetero-, mixotrophy) when defense is present in the model. Moreover, the inclusion of defense tradeoffs relaxes in most scenarios the strong trophic cascade seen in the absence of defense and leads to increased coexistence between size classes. In particular, the intermediate size classes are subject to an increase in biomass.. The increase in diversity and the effect of defense on community structure are, however, tempered by the choices of the trade-off formulation in terms of the shape of the competitive abilities/defense relationships and - in the case of a linear defense trade-off - also by the process on which the cost penalty is paid. When, for example, defense costs are paid as reduce nutrient affinity rather than elevated metabolic expenses, the costs become negligible under eutrophic conditions and strong defense and coexistence between size classes is more pronounced under such conditions. Under oligotrophic conditions, cheap defenses have stronger impact on community structure because defense costs become relatively more important, and scenario with a linear competition/defense curve selects mostly 
undefended types with larger size diversity. The shape of the trade-off and the cost penalty of the defense may vary between different mechanisms and, hence, a correct model choice requires a mechanistic understanding of the defense and its costs.

\section{Defense mechanisms and their costs in unicellular plankton}

It is often not obvious whether defense results in a decreased ability to harvest resources (lower affinity) or in an elevated metabolic rate in the defended cell, nor what the defense costs at all are (Pančić and Kiørboe 2018). To illustrate, consider the examples of dinoflagellates that produce toxins and consequently experience a lower grazing mortality (Teegarden 1999, Xu and Kiørboe 2018) and diatoms that encapsulate themselves in a hard shell supposed to provide protection against grazers (Hamm et al. 2003, Liu et al. 2016). Several studies have demonstrated a negative relation between dinoflagellate toxin content and both affinity and growth rate when comparing different species or strains (Frangópulos et al. 2004, Brandenburg 2018), suggesting costs in both terms. However, others have failed to demonstrate such relations (John et al. 2015) and studies comparing the growth rate of toxin producing and non-producing cells of the same strain have similarly been unable to demonstrate any costs (Selander et al. 2006). Hence, the picture is rather unclear. However, toxin production is inducible, i.e., produced in much higher quantities in the presence of grazer cues (Selander et al. 2006), strongly suggesting that toxin production is indeed costly, but the costs may only materialize when resources are limiting (Chakraborty et al. 2018).

The case of diatoms is different but similarly unclear. The biochemical costs of synthesizing silica are negligible (Raven 1983) and there is no evidence that a siliceous shell hampers nutrient affinity, rather the opposite (Mitchell et al. 2013). However, silica deposition is rate limited and happens only during a particular (G2) phase of the growth cycle and, hence, slower growing cells deposit a thicker shell (Brzezinski et al. 1990). To the extent that shell thickening is inducible (Pondaven et al. 2007) and 
accompanied by a reduced growth rate to allow time for increased silica deposition, the costs mainly materialize as a reduced growth, equivalent to (but mechanistically different from) a metabolic defense cost.

The cost of defense will in most cases likely be 'cheap', i.e., the investment results in diminishing returns with high benefits initially and reduced additional benefits with increasing investment $(\tau<1)$. For example, cell toxins may have grazer deterrent effects but the grazer response must be a saturating function of toxin content that asymptotically approaches 'no grazing'. For the diatom case, a reduction in growth rate may result in an identical fractional increase in shell thickness, but shell strength increases with thickness cubed (Gutiérrez et al. 2017) and the shell thus rapidly becomes 'uncrack-able', and any further increase in thickness does not provide further protection. Most other defense mechanisms we can think of similarly have diminishing returns on the investment. To the extent that this is true, this will relax the requirement for a correct model formulation of how the defense costs are paid, because at low $\tau$ this has limited effect on the resulting community structure, both at steady state (Figs 3 to 6) and in a seasonal environment (Fig. 7). However, again, quantitative insights in the shape of the trade-off are essentially non-existent.

\section{Inducible defenses}

As noted above, many defense mechanisms are inducible, i.e., they are harnessed only in the presence of predation risk. Such phenotypic defense plasticity may have major impact on predator-prey interactions (Someren Gréve et al. in press), populations dynamics (Kishida et al. 2010), community structure (Miner et al. 2005), and ecosystem function (Schmitz and Suttle 2001), and the effects may depend on whether the defense response is immediate (e.g., behavior) or delayed (e.g., morphological defenses) (Yamanamichi et al. 2019). Inducible defense is implicitly included in our model: at steady state the emerging defense strategies can arise due to the occurrence of different 
species with fixed defenses, or due to induced defenses; our trait-based model does not distinguish the two, and the emerging community structure is independent on whether the defense is immediate or delayed. In the simulation of the dynamics in a seasonal cycle, our model implicitly assumes a delayed response because cell abundances, and hence defense strategies, change according to growth/mortality under the prevailing conditions. This partly resembles induction with a trans-generational delay, such as colony formation or shape change, or elevated production of toxins that requires multiple days of exposure to grazer cues to become expressed. The emergent seasonal cycle may be different for immediate defense responses but this has not been explored here.

\section{The relation between defense and trophic strategies}

Due to the different size-scaling of the affinities for light, nutrients, and prey (Andersen et al. 2016) small cells tend to be mainly autotrophic, large cells heterotrophic, and intermediately sized cells mixotrophic (Fig. 4), but cells of all sizes have the possibility of being mixotrophic if environmental resource composition favors that in our model. This possibility is consistent with the emerging consensus that most flagellates are potentially mixotrophic (Flynn et al. 2013). The uptake of organic nitrogen through predation is a way to overcome inorganic resource limitation (Stoecker et al. 1997. Samuelsson et al. 2002). Therefore, mixotrophs are able to increase their competitive ability during the summer in low-nutrients regions such as the surface layer of seasonally stratified seas, and in the oligotrophic subtropical gyres (Unrein et al. 2007). This is consistent with the predicted dominance of mixotrophy under oligotrophic steady-state conditions (Fig. 4 b) and during the summer in the seasonally varying environment in the present study.

We have here in addition shown that investment in resistance against predation promotes the occurrence of the mixotrophic strategies under eutrophic conditions at 
steady state. Indeed, whereas autotrophy and heterotrophy are the dominant resource acquisition modes under non-limiting conditions in the absence of defense mechanisms, the incorporation of defense essentially promotes higher abundance of intermediate sized mixotrophs (Fig. 4a), again, however, somewhat depending on the formulation of the trade-off (Fig. 7).

Toxic dinoflagellates (e.g. Alexandrium sp.) are defended mixotrophs and a group of organisms known to form toxic algal blooms (TAB; Burkholder et al. 2008). Such blooms are usually observed under summer conditions of nutrient limitation and concurrent with the stabilization of the water column (Hakanen et al. 2012, Gettings et al. 2014, Sourisseau et al. 2017) and the highest seasonal abundance of copepod grazers (Kiørboe and Nielsen 1994). These are the conditions that stimulate the induction of costly defense in dinoflagellates (Chakraborty et al. 2018). While this is consistent with the predictions of our model (i.e. prevalence of high defense among mixotrophs during the nutrient limited period in summer when cost of defense materializes as a reduced nutrient affinity), the model itself does not predict blooms as such. This suggests that additional features are required to facilitate a bloom, such as the production of lytic substances that may kill competing phytoplankton as often found among toxic dinoflagellates (John et al. 2015, Xu et al. 2017), physical advection that may concentrate cells or bring them to the surface (Glibert et al. 2005), or other mechanisms.

\section{Model limitations}

In addition to the limitations noted above, there are at least two key limitations of our model. First, while we have discussed two of the most common defense mechanism among marine unicellular plankton, a protective shell as found in diatoms and the production of toxins, our model does not explicitly consider diatoms that account for about half the global ocean primary production (Nelson et al. 1995). Diatoms differ from flagellates in that they are obligate autotrophs and do not have the ability of 
heterotrophic resource acquisition. In addition, diatoms typically grow faster than other phytoplankton, likely because their sizes are inflated by a big central vacuole that enhances the mass-specific nutrient uptake rates (Thingstad et al. 2005). The inclusion of this life form may therefore change the dynamics and composition of the model plankton community.

A second limitation is that we do not explicitly simulate the population dynamics of multicellular higher trophic levels that are here included only as a constant predation rate on the three largest size classes. However, multicellular grazers, like copepods, have ontogenetic prey size shifts (Berggreen et al. 1988) which on its own may promote coexistence and prey diversity (Palkovacs and Post 2008, 2009, Wollrab et al. 2013) and dampen the cascading effects observed in our model (Post et al. 2008); i.e., effects that are similar to the effects of defense trade-offs.

\section{Conclusions}

Our findings demonstrate the significance of the competition/defense trade-off in determining the seasonal succession and community composition of unicellular plankton. The diverse expressions of strategies along the competition-defense and foraging trait dimensions radically alter not only the diversity and structure of the community, but most likely also its function in terms of trophic transfer, recycling, and export flux. While the current model is insufficiently consolidated to explore this in any detail, the efficiency by which primary production is channeled to higher trophic levels, and consequently the efficiency of, e.g., carbon sequestration, varies significantly between the different defense scenarios examined (Figs 3, 6, 7). The promotion of mixotrophy by defense trade-offs, for example, is likely to enhance the efficiency of the biological carbon pump, since mixotrophy increases trophic transfer efficiencies and the sinking of particulate organic matter to the ocean interior (Ward and Follows 2016). Global ocean biogeochemical models have only a fairly recent history of considering 
trophic strategies with respect to, e.g., nitrogen fixation (Dutkiewicz et al. 2014), mixotrophy (Ward and Follows 2016, Ghyoot et al. 2017), or zooplankton foraging behavior (Prowe et al. 2012). Like defense itself, these trophic strategies have a strong structuring effect on plankton communities and their biogeochemical implications.

A severe limitation to further develop trait-based models that considers the structuring effects of defense is the poor mechanistic understanding of defense mechanisms in unicellular plankton (Pančić and Kiørboe, 2018). The work presented here has both demonstrated the significance of defense in structuring plankton communities and has identified the key characteristics of defense mechanisms that need to be quantified: the magnitudes of the costs and benefits, the shape of the trade-off, and how defense costs materializes. These insights may be helpful in designing future experimental approaches aiming at filling the gaps in our mechanistic understanding of plankton defenses and the subsequent development of more correct models and deeper understanding of plankton community structure and function.

\section{Acknowledgements}

We acknowledge support from the Gordon \& Betty Moore Foundation through award \#5479. The Centre for Ocean Life is a Villum Kahn Rasmussen Centre of Excellence funded by the Villum Foundation.

\section{References}

Andersen, K. H. et al. 2016. Characteristic sizes of life in the oceans, from bacteria to whales. - Annual Review of Marine Science 8: 217-241.

Berggreen, U. et al. 1988. Food size spectra, ingestion and growth of the copepodAcartia tonsa during development: Implications for determination of copepod production. - Marine biology 99: 341-352.

Boots, M. 2011. The evolution of resistance to a parasite is determined by resources. The American Naturalist 178: 214-220.

Boots, M. and Haraguchi, Y. 1999. The evolution of costly resistance in host-parasite 
systems. - The American Naturalist 153: 359-370.

Brandenburg, K. M. et al. 2018. Intraspecific trait variation and trade-offs within and across populations of a toxic dinoflagellate. - Ecology letters 21: 1561-1571.

Brzezinski, M. A. et al. 1990. Silicon availability and cell-cycle progression in marine diatoms. - Marine ecology progress series: 83-96.

Burkholder, J. M. et al. 2008. Mixotrophy, a major mode of nutrition for harmful algal species in eutrophic waters. - Harmful Algae 8: 77-93.

Cadier, M. et al. 2017. Assessing spatial and temporal variability of phytoplankton communities' composition in the Iroise Sea ecosystem (Brittany, France): A 3D modeling approach. Part 1: Biophysical control over plankton functional types succession and distribution. - Journal of Marine Systems 165: 47-68.

Chakraborty, S. et al. 2017. Trophic strategies of unicellular plankton. - The American Naturalist 189: E77-E90.

Chakraborty, S. et al. 2018. The cost of toxin production in phytoplankton: the case of PST producing dinoflagellates. - The ISME Journal: 1.

Chesson, P. 1991. A need for niches? - Trends in ecology \& evolution 6: 26.

Duffy, J. E. and Stachowicz, J. J. 2006. Why biodiversity is important to oceanography:: potential roles of genetic, species, and trophic diversity in pelagic ecosystem processes. - Marine Ecology Progress Series 311: 179-190.

Dutkiewicz, S. et al. 2014. Understanding predicted shifts in diazotroph biogeography using resource competition theory. - Biogeosciences in press.

Ehrlich, E. and Gaedke, U. 2018. Not attackable or not crackable-How pre- and postattack defenses with different competition costs affect prey coexistence and population dynamics. - Ecology and Evolution 8: 6625-6637.

Evans, G. T. and Parslow, J. S. 1985. A model of annual plankton cycles. - Biological oceanography 3: 327-347.

Flynn, K. J. et al. 2013. Misuse of the phytoplankton-zooplankton dichotomy: the need to assign organisms as mixotrophs within plankton functional types. - J Plankton Res 35: 3-11.

Frangópulos, M. et al. 2004. Toxin production and competitive abilities under phosphorus limitation of Alexandrium species. - Harmful Algae 3: 131-139.

Gettings, R. M. et al. 2014. Dynamics of late spring and summer phytoplankton communities on Georges Bank, with emphasis on diatoms, Alexandrium spp., and other dinoflagellates. - Deep Sea Research Part II: Topical Studies in Oceanography 103: 120-138.

Ghyoot, C. et al. 2017. Introducing mixotrophy into a biogeochemical model describing an eutrophied coastal ecosystem: The Southern North Sea. - Progress in Oceanography 157: 1-11. 
Glibert, P. M. et al. 2005. The global, complex phenomena of harmful algal blooms. Oceanography 18: 136-147.

Grover, J. P. 1995. Competition, herbivory, and enrichment: nutrient-based models for edible and inedible plants. - The American Naturalist 145: 746-774.

Gutierrez, A. et al. 2017. Deformation modes and structural response of diatom frustules. - J. Mater. Sci. Eng. Adv. Technol. 15: 105-134.

Hakanen, P. et al. 2012. Bloom and toxin dynamics of Alexandrium ostenfeldii in a shallow embayment at the SW coast of Finland, northern Baltic Sea. - Harmful Algae 15: 91-99.

Hamm, C. E. et al. 2003. Architecture and material properties of diatom shells provide effective mechanical protection. - Nature 421: 841.

Hansen, B. et al. 1994. The size ratio between planktonic predators and their prey. Limnology and Oceanography 39: 395-403.

Hartvig, M. et al. 2011. Food web framework for size-structured populations. - Journal of Theoretical Biology 272: 113-122.

Holt, R. D. et al. 1994. Simple rules for interspecific dominance in systems with exploitative and apparent competition. - The American Naturalist 144: 741-771.

Huisman, J. et al. 2001. Towards a solution of the plankton paradox: the importance of physiology and life history. - Ecology Letters 4: 408-411.

Hutchinson, G. E. 1961. The paradox of the plankton. - The American Naturalist 95: $137-145$.

John, U. et al. 2015. Intraspecific facilitation by allelochemical mediated grazing protection within a toxigenic dinoflagellate population. - Proceedings of the Royal Society of London B: Biological Sciences 282: 20141268.

Kiørboe, T. and Nielsen, T. G. 1994. Regulation of zooplankton biomass and production in a temperate, coastal ecosystem. 1. Copepods. - Limnology and Oceanography 39: 493-507.

Kiørboe, T. et al. 2014. Flow disturbances generated by feeding and swimming zooplankton. - Proceedings of the National Academy of Sciences 111: 1173811743.

Kishida, O. et al. 2010. Evolutionary ecology of inducible morphological plasticity in predator-prey interaction: toward the practical links with population ecology. Population ecology 52: 37-46.

Kraaijeveld, A. R. and Godfray, H. C. J. 1997. Trade-off between parasitoid resistance and larval competitive ability in Drosophila melanogaster. - Nature 389: 278.

Leibold, M. A. 1989. Resource edibility and the effects of predators and productivity on the outcome of trophic interactions. - The American Naturalist 134: 922-949.

Leibold, M. A. et al. 2017. Herbivory enhances the diversity of primary producers in 
pond ecosystems. - Ecology 98: 48-56.

Levin, S. A. 1970. Community Equilibria and Stability, and an Extension of the Competitive Exclusion Principle. - The American Naturalist 104: 413-423.

Liu, H. et al. 2016. Effect of diatom silica content on copepod grazing, growth and reproduction. - Frontiers in Marine Science 3: 89.

Loeuille, N. and Loreau, M. 2004. Nutrient enrichment and food chains: can evolution buffer top-down control? - Theoretical population biology 65: 285-298.

Lynch, M. and Shapiro, J. 1981. Predation, enrichment, and phytoplankton community structure1. - Limnol. Oceanogr. 26: 86-102.

McCauley, E. and Briand, F. 1979. Zooplankton grazing and phytoplankton species richness: Field tests of the predation hypothesis1. - Limnology and Oceanography 24: 243-252.

Miner, B. G. et al. 2005. Ecological consequences of phenotypic plasticity. - Trends in ecology \& evolution 20: 685-692.

Mitchell, J. G. et al. 2013. The role of diatom nanostructures in biasing diffusion to improve uptake in a patchy nutrient environment. - PLoS One 8: e59548.

Nelson, D. M. et al. 1995. Production and dissolution of biogenic silica in the ocean: revised global estimates, comparison with regional data and relationship to biogenic sedimentation. - Global Biogeochemical Cycles 9: 359-372.

Palkovacs, E. P. and Post, D. M. 2008. Eco-evolutionary interactions between predators and prey: can predator-induced changes to prey communities feed back to shape predator foraging traits? - Evol Ecol Res 10: 699-720.

Pančić, M. and Kiørboe, T. 2018. Phytoplankton defence mechanisms: traits and tradeoffs. - Biological Reviews 93: 1269-1303.

Pondaven, P. et al. 2007. Grazing-induced changes in cell wall silicification in a marine diatom. - Protist 158: 21-28.

Post, D. M. et al. 2008. Intraspecific Variation in a Predator Affects Community Structure and Cascading Trophic Interactions. - Ecology 89: 2019-2032.

Prowe, A. F. et al. 2012. Top-down control of marine phytoplankton diversity in a global ecosystem model. - Progress in Oceanography 101: 1-13.

Raven, J. A. 1983. The transport and function of silicon in plants. - Biological Reviews 58: 179-207.

Samuelsson, K. et al. 2002. Structural changes in an aquatic microbial food web caused by inorganic nutrient addition. - Aquatic Microbial Ecology 29: 29-38.

Scheffer, M. et al. 2003. Why plankton communities have no equilibrium: solutions to the paradox. - Hydrobiologia 491: 9-18.

Schmitz, O. J. and Suttle, K. B. 2001. Effects of top predator species on direct and indirect interactions in a food web. - Ecology 82: 2072-2081.

'This article is protected by copyright. All rights reserved.' 
Selander, E. et al. 2006. Copepods induce paralytic shellfish toxin production in marine dinoflagellates. - Proceedings of the Royal Society of London B: Biological Sciences 273: 1673-1680.

Shampine, L. and Reichelt, M. 1997. The MATLAB ODE Suite. - SIAM J. Sci. Comput. 18: 1-22.

Shannon, C. E. 1948. A Mathematical Theory of Communication. - Bell system technical journal 27: 379-423.

Someren Gréve, H. and Almeda, R. 2019. Bottom-up behaviorally mediated trophic cascades in plankton food webs. - Roy. Soc. B. (in press)

Sourisseau, M. et al. 2017. Resource Competition Affects Plankton Community Structure; Evidence from Trait-Based Modeling. - Front. Mar. Sci. 4: 52.

Sterner, R. W. 1989. The Role of Grazers in Phytoplankton Succession. - In: Plankton Ecology. Brock/Springer Series in Contemporary Bioscience. Springer, Berlin, Heidelberg, pp. 107-170.

Stoecker, D. K. et al. 1997. Mixotrophy in the dinoflagellate Prorocentrum minimum. Marine Ecology Progress Series 152: 1-12.

Teegarden, G. J. 1999. Copepod grazing selection and particle discrimination on the basis of PSP toxin content. - Marine Ecology Progress Series 181: 163-176.

Thingstad, T. F. et al. 2005. Use of non-limiting substrates to increase size; a generic strategy to simultaneously optimize uptake and minimize predation in pelagic osmotrophs? - Ecology Letters 8: 675-682.

Tilman, D. 1982. Resource competition and community structure. - Princeton university press.

Unrein, F. et al. 2007. Significant year-round effect of small mixotrophic flagellates on bacterioplankton in an oligotrophic coastal system. - Limnol. Oceanogr. 52: 456-469.

Våge, S. et al. 2014. Optimal defense strategies in an idealized microbial food web under trade-off between competition and defense. - PloS one 9: e101415.

Våge, S. et al. 2018. Simple models combining competition, defence and resource availability have broad implications in pelagic microbial food webs. - Ecology letters 21: 1440-1452.

Viola, D. V. et al. 2010. Competition-defense tradeoffs and the maintenance of plant diversity. - Proceedings of the National Academy of Sciences 107: 1721717222.

Ward, B. A. and Follows, M. J. 2016. Marine mixotrophy increases trophic transfer efficiency, mean organism size, and vertical carbon flux. - PNAS 113: 29582963.

Winter, C. et al. 2010. Trade-Offs between Competition and Defense Specialists among Unicellular Planktonic Organisms: the "Killing the Winner" Hypothesis 
Revisited. - Microbiol. Mol. Biol. Rev. 74: 42-57.

Wolfe, G. V. 2000. The chemical defense ecology of marine unicellular plankton: constraints, mechanisms, and impacts. - The Biological Bulletin 198: 225-244.

Wollrab, S. et al. 2013. Ontogenetic diet shifts promote predator-mediated coexistence. - Ecology 94: 2886-2897.

Xu, J. and Kiørboe, T. 2018. Toxic dinoflagellates produce true grazer deterrents. Ecology 99: 2240-2249.

$\mathrm{Xu}$, J. et al. 2017. Distinctly different behavioral responses of a copepod, Temora longicornis, to different strains of toxic dinoflagellates, Alexandrium spp. Harmful algae 62: 1-9.

Yamamichi, M. et al. 2018. Modelling inducible defences in predator-prey interactions: assumptions and dynamical consequences of three distinct approaches. Ecology letters in press. 


\section{Figures Legends}

Figure 1: (a) Trade-off curves demonstrating how the gain of defense (decreased predation mortality) varies with the cost (reduced competitive ability) for different values of $\tau$. When $\tau=1$ (blue line), the gain is proportional to the cost. For $\tau<1$ (orange and black lines), the gain increases at a decelerating rate with increasing cost (diminishing return). For $\tau>1$ (not shown), the gain increases with the cost at an accelerating rate; this situation is unlikely in nature. (b) Schematic of cell with illustrating resource fluxes and where defense costs are paid, as reduced affinity for nutrients (1) and food (2), or as reduced growth due to resource allocation to defense (3). (c) Schematic of food web model with 9 size classes that are each distributed among 11 different defense strategies. Resource flows are illustrated by arrows of different colors; arrow thickness indicate flux intensities

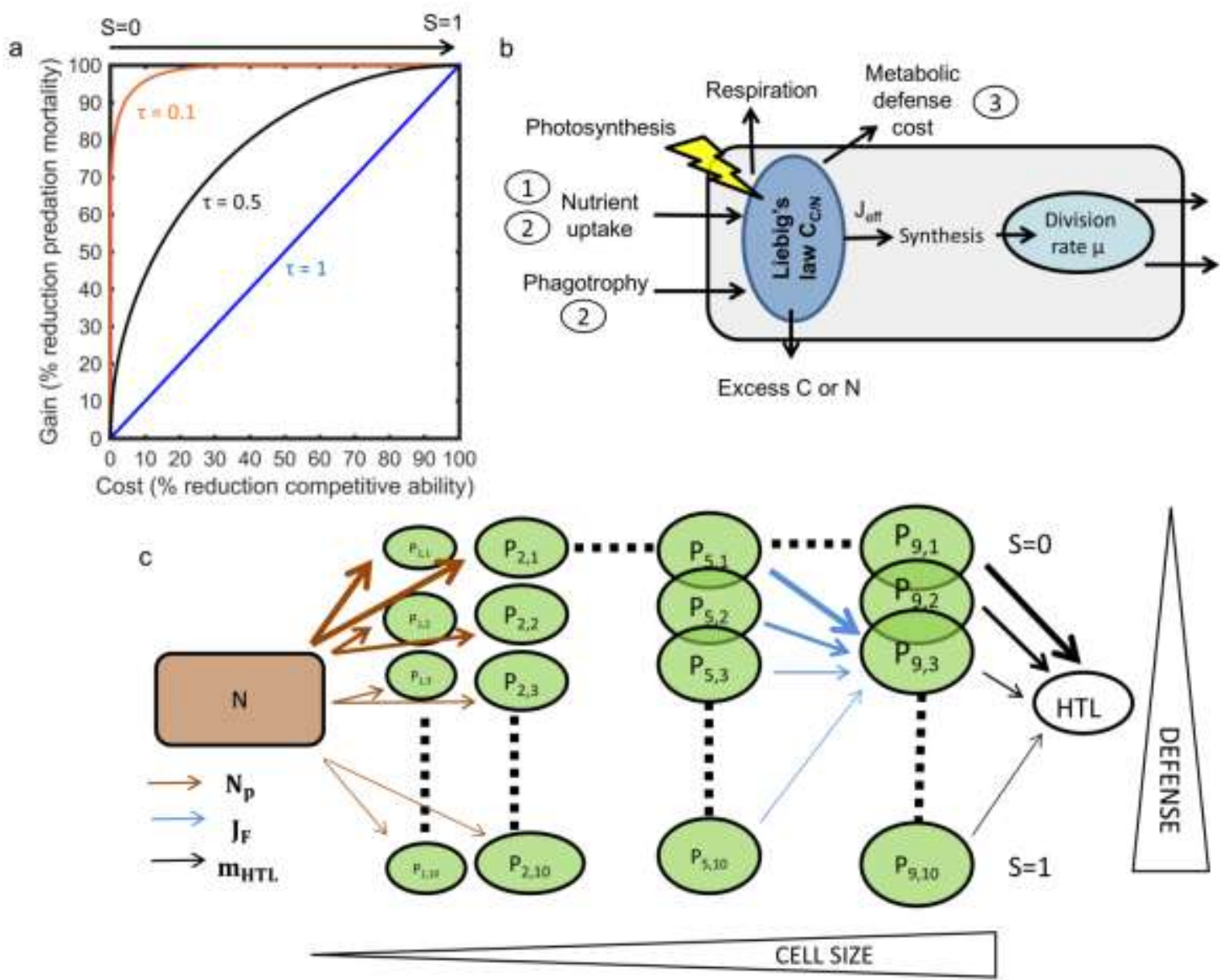

'This article is protected by copyright. All rights reserved.' 
Figure 2: Temporal variation of light $\left(\mathrm{W} \mathrm{m}^{-2}\right.$; blue line $)$ and dilution rate $\left(\mathrm{d}^{-1}\right.$; black line) used in the seasonal simulations.

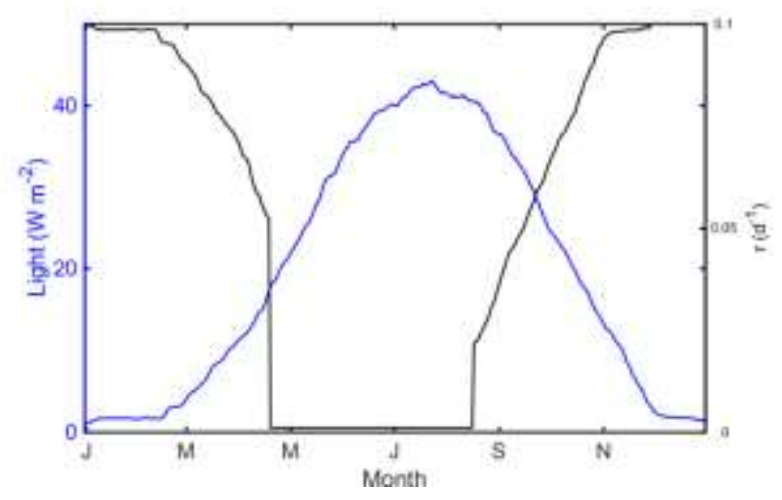


Figure 3: Steady state size distribution of biomass $\left(\mathrm{gC} \mathrm{m}^{-3}\right)$ in the absence of defense and with defense for different shapes of the trade-off ( $\tau=1$ (blue line): expensive defense (blue line) and $\tau=0.1$ (orange line): cheap defense) when cost of defense materializes as reduction of inorganic nutrients affinity $\left(\mathbf{A}_{\mathbf{N}}\right.$; $\left.a-b\right)$; reduction of inorganic nutrients and food affinity or $\left(\mathbf{A}_{\mathbf{N}}+\mathbf{A}_{\mathbf{F}} ; \mathbf{c}-\mathrm{d}\right)$ or as additional metabolic cost (Add. Cost.; e-f). Results are presented in eutrophic (left column; $\mathrm{N}_{0}=12 \mathrm{mmol} \mathrm{N} \mathrm{m}^{-3}$ ) and oligotrophic conditions (left column; $\mathrm{N}_{0}=1 \mathrm{mmol} \mathrm{N} \mathrm{m}{ }^{-3}$ ).
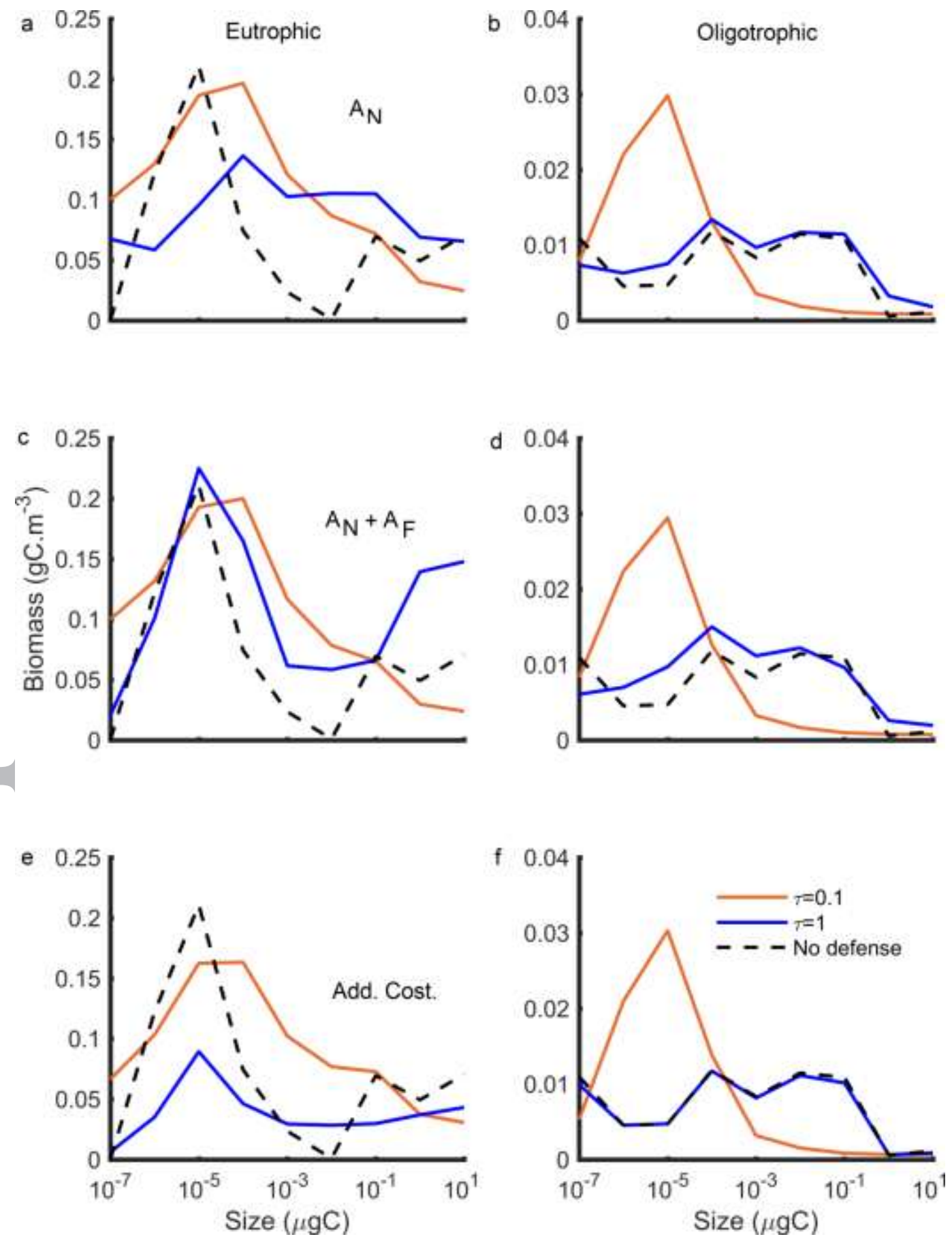

'This article is protected by copyright. All rights reserved.' 
Figure 4: Mean trophic strategies as a function of cell size at steady state in (a) eutrophic and (b) oligotropohic conditions for different cost formulations. The average trophic strategy varies between pure autotrophy (0) and pure heterotrophy (1). All results are for $\tau=1$. The shaded areas show the standard deviation of mean trophic strategy when defense is paid as reduced nutrient affinity (in other cases the standard deviation is 0 ).

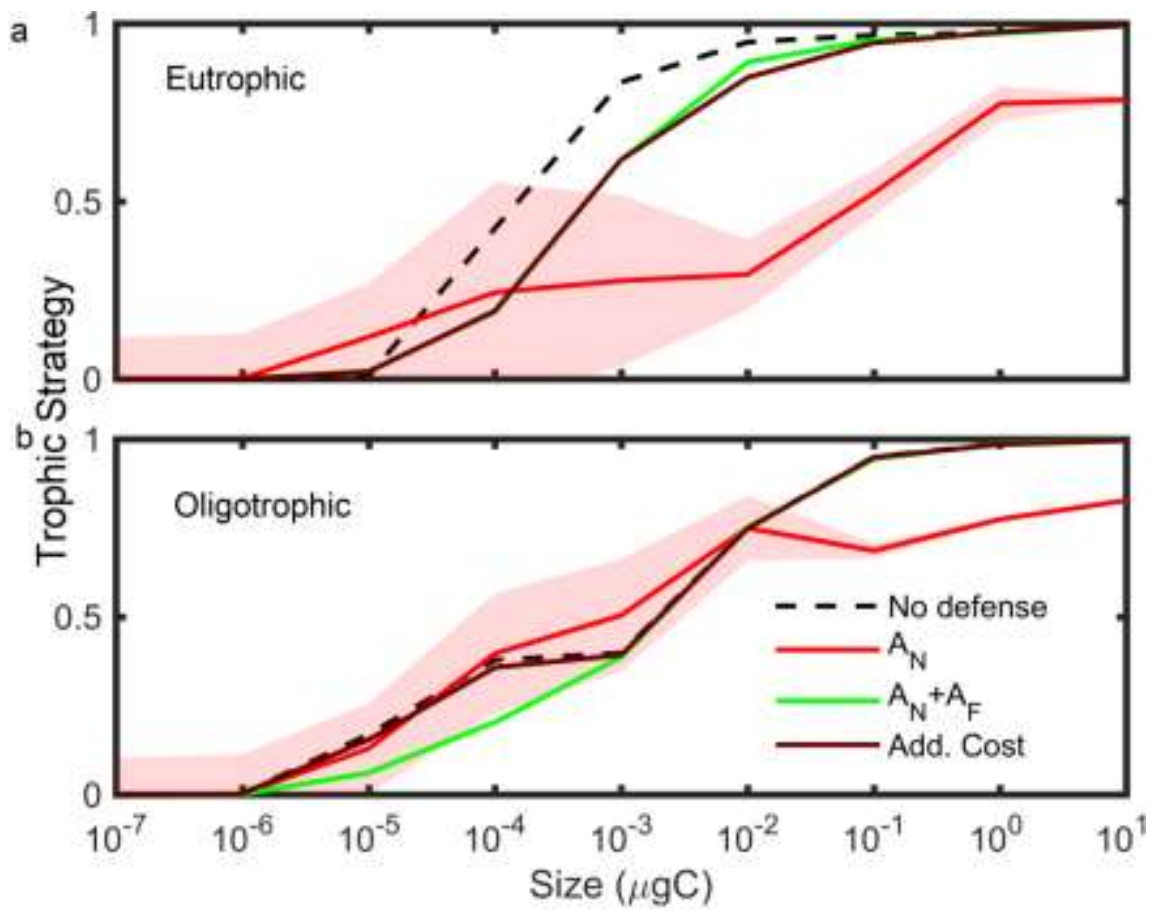

'This article is protected by copyright. All rights reserved.' 
Figure 5: Shannon-Wiener diversity Index at steady state in simulations without defense (dotted lines) and as a function of the trade-off parameter $\tau$ for the different cost formulations in (a) eutrophic and (b) oligotrophic conditions.

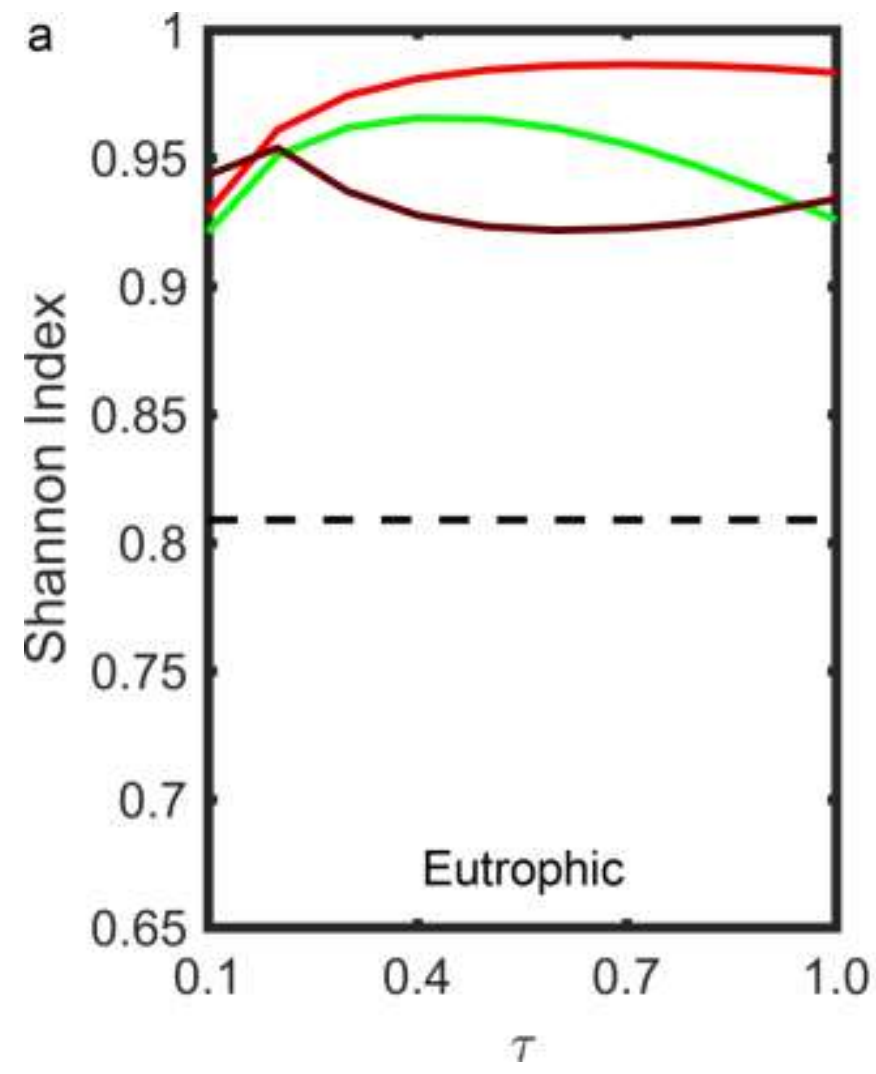

b

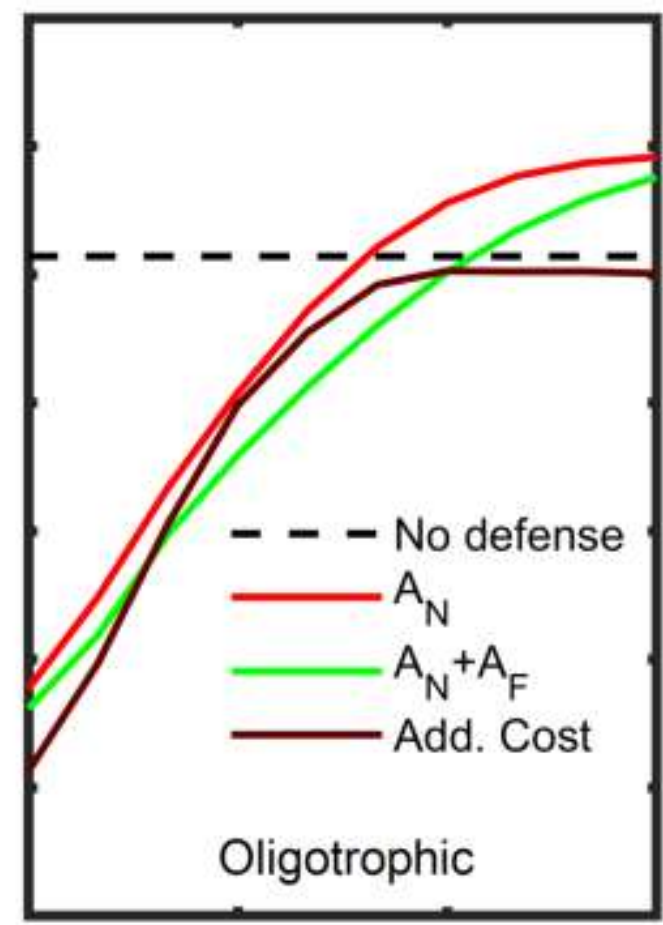

$\begin{array}{llll}0.1 & 0.4 & 0.7 & 1.0\end{array}$


Figure 6: Steady state biomass distribution $\left(\mathrm{gC} \mathrm{m}^{-3}\right)$ in the plankton compartments as a function of size and defense strategy in eutrophic (left column) and oligotrophic (right column) conditions and for $\tau=0.1$ (a-f) or $\tau=1(\mathrm{~g}-\mathrm{l})$. Results are presented for the different formulation of the cost: ( $\mathrm{a}, \mathrm{b}, \mathrm{g}$ and $\mathrm{h}$ ) cost applied to affinity for inorganic nutrients only; (c, d, i and j) cost applied to nutrients and food affinities and (e, f, k and 1) cost applied as additional metabolic expenditures.
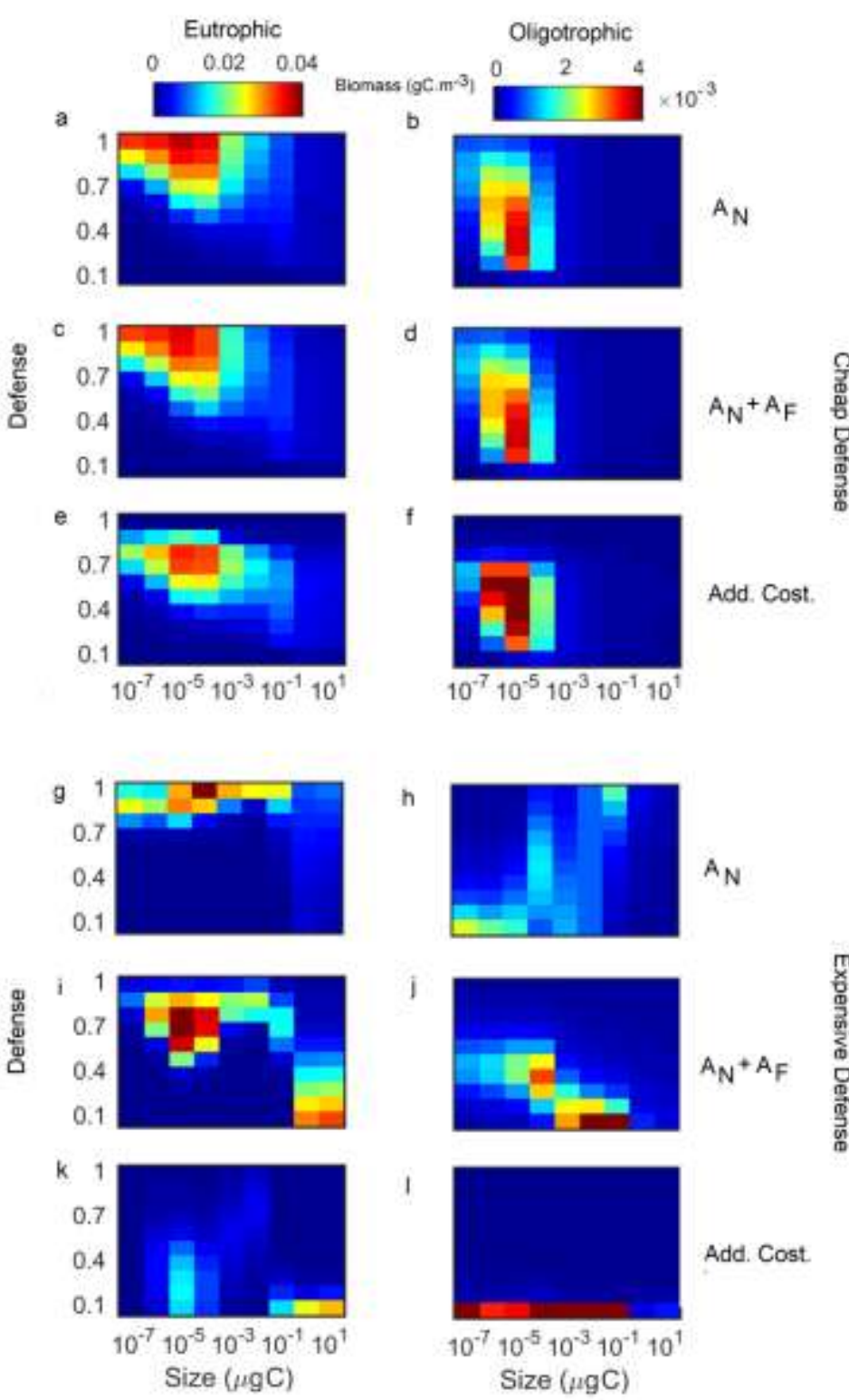

h
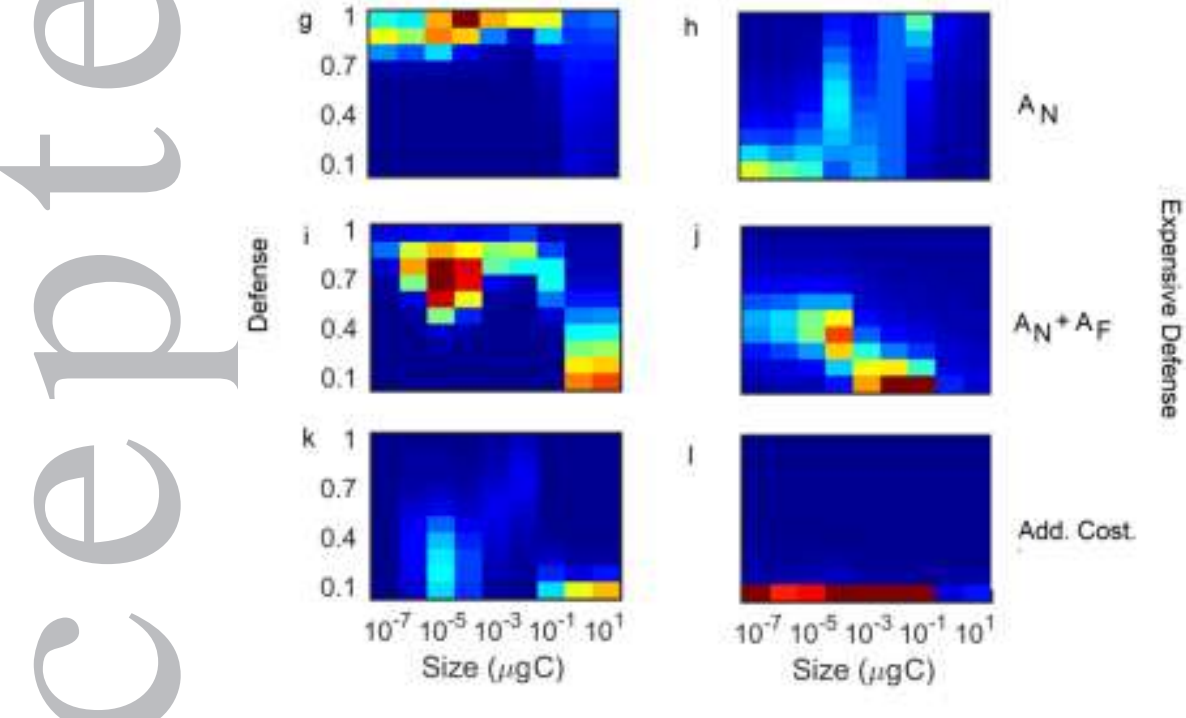
Figure 7: Seasonal variation in biomass distribution (left column), size-dependent mean defense strategy (middle column), and size-dependent mean trophic strategy (right column). Simulations are made without defense (a,b), with defense cost applied on nutrient affinity (c-e: $\tau=0.1$ and f-h: $\tau=1$ ), with defense cost on nutrient and food affinities $(\tau=1 ; \mathrm{i}-\mathrm{k})$, and defense cost as additional metabolic expenditures $(\tau=1 ; 1-\mathrm{n})$.

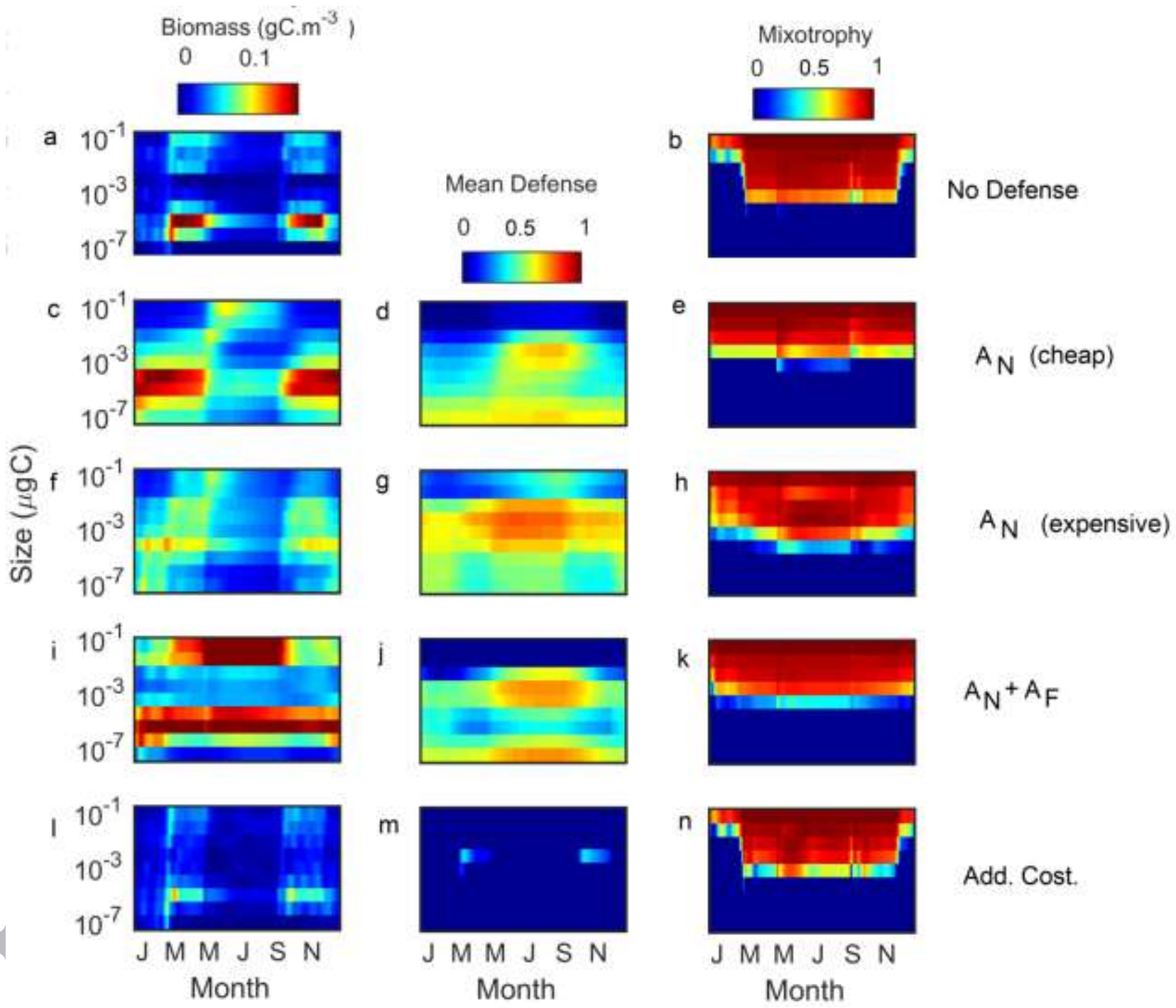


Tables Legends

Table 1: Model parameters: symbols, meaning, values, and units.

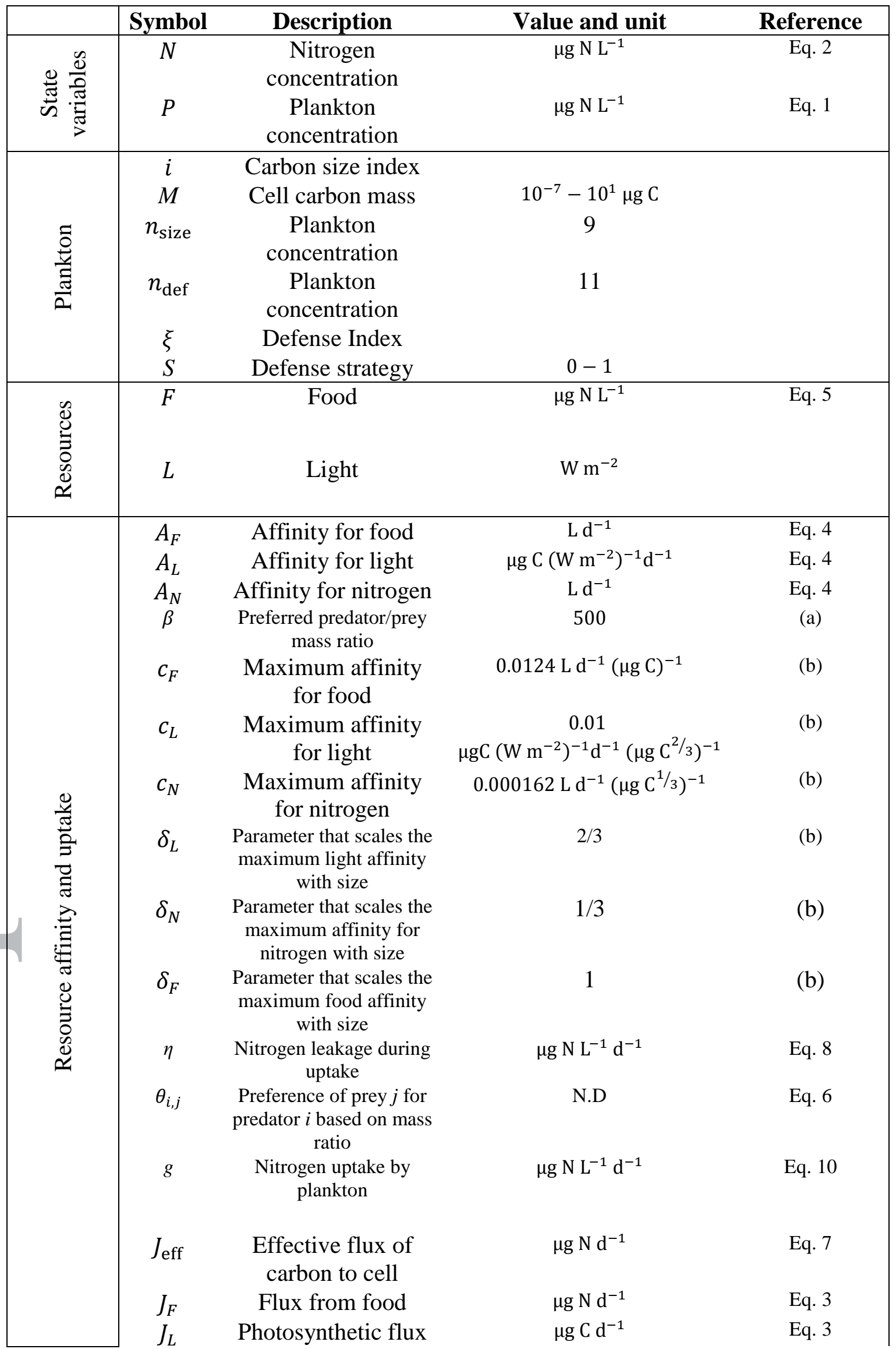

'This article is protected by copyright. All rights reserved.' 


\begin{tabular}{|c|c|c|c|c|}
\hline & $\begin{array}{l}J_{N} \\
R_{0}\end{array}$ & $\begin{array}{l}\text { Nitrogen flux } \\
\text { Respiration loss }\end{array}$ & $\begin{array}{l}\mu \mathrm{g} \mathrm{N} \mathrm{d}^{-1} \\
0.04 \mathrm{~d}^{-1}\end{array}$ & $\begin{array}{l}\text { Eq. } 3 \\
\text { (b) }\end{array}$ \\
\hline & $\sigma$ & $\begin{array}{l}\text { Niche width for predator } \\
\text { preferences for prey size }\end{array}$ & 1.22 & (a) \\
\hline \multirow{3}{*}{ 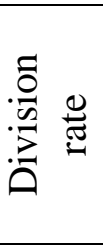 } & $f$ & $\begin{array}{l}\text { Limitation of } \\
\text { biosynthesis }\end{array}$ & N.D & Eq. 9 \\
\hline & $\mu$ & Division rate & $d^{-1}$ & Eq. 9 \\
\hline & $\mu_{\max }$ & $\begin{array}{l}\text { Maximal division rate of } \\
\text { plankton }\end{array}$ & $1 d^{-1}$ & \\
\hline \multirow{4}{*}{ 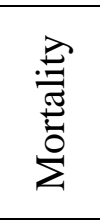 } & $m_{0}$ & Quadratic mortality term & $0.001 \mathrm{~L} \mu \mathrm{gC}^{-1} \mathrm{~d}^{-1}$ & (c) \\
\hline & $m_{\mathrm{HTL} 0, i}$ & Predation by higher & $\mathrm{P}_{7}: 0.03 \mathrm{~d}^{-1}$ & (c) \\
\hline & & $\begin{array}{l}\text { trophic levels plankton } \\
\qquad P_{i}\end{array}$ & $\begin{array}{l}P_{8}: 0.05 d^{-1} \\
P_{9}: 0.06 d^{-1}\end{array}$ & \\
\hline & $m_{p}$ & Predation loss mortality & $\mathrm{d}^{-1}$ & Eq. 11 \\
\hline \multirow{5}{*}{ 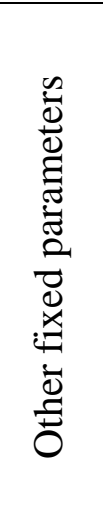 } & $c_{\mathrm{CN}}$ & $\begin{array}{l}\mathrm{C} / \mathrm{N} \text { ratio in plankton } \\
\text { cells }\end{array}$ & $5.68 \mu \mathrm{g} \mathrm{C} / \mu \mathrm{g} \mathrm{N}$ & \\
\hline & $N_{0}$ & $\begin{array}{l}\text { Background nitrogen } \\
\text { concentration }\end{array}$ & $\begin{array}{c}14 \text { (oligotrophic) } \\
168 \text { (eutrophic) } \mu \mathrm{g} \mathrm{N} . \mathrm{L}^{-1}\end{array}$ & \\
\hline & $P_{0}$ & $\begin{array}{l}\text { Background } \\
\text { plankton } \\
\text { concentration }\end{array}$ & $0.001 \mathrm{~N}_{0} \mu \mathrm{g} \mathrm{N} . \mathrm{L}^{-1}$ & \\
\hline & $r$ & $\begin{array}{l}\text { Dilution rate in the } \\
\text { chemostat }\end{array}$ & $0.1 \mathrm{~d}^{-1}$ & \\
\hline & $\tau$ & $\begin{array}{l}\text { Competition/defense } \\
\text { trade-off shape } \\
\text { parameter }\end{array}$ & $0.1-1$ & \\
\hline
\end{tabular}

(a) Hansen et al., 1994; (b) Chakraborty et al., 2017; (c) Closure parameters have been adjusted such as viral lysis and higher trophic levels predation are of low impact on the model dynamics compared to internal processes (predation). 


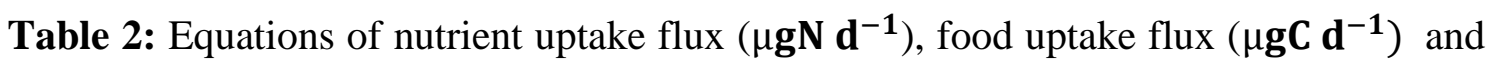
effective growth rate $\left(\mathbf{d}^{\mathbf{- 1}}\right)$ when cost of defense materializes as (1) reduced nutrient affinity only $\left(A_{N}\right)$, (2) reduced affinity for both nutrient and food $\left(A_{N}+A_{F}\right)$ or (3) elevated metabolic expenditure (Add. Cost.).

\begin{tabular}{|c|c|c|c|}
\hline $\begin{array}{c}\text { Cost } \\
\text { Formulation }\end{array}$ & Nutrient Uptake & Food Uptake & Division rate \\
\hline 1. $A_{N}$ & $J_{N}=(1-S)^{\tau} A_{\mathrm{N}} N$ & $J_{F}=A_{\mathrm{F}} F$ & $\mu=\mu_{\text {max }} \quad J_{\text {eff }}$ \\
\hline 2. $A_{N}+A_{F}$ & $J_{N}=(1-S)^{\tau} A_{\mathrm{N}} N$ & $J_{F}=(1-S)^{\tau} A_{\mathrm{F}} F$ & $\mu=\mu_{\max } \overline{J_{e f f}+\mu_{\max } M}$ \\
\hline 3. Add. Cost & $J_{N}=A_{\mathrm{N}} N$ & $J_{F}=A_{\mathrm{F}} F$ & $\mu \quad J_{e f f}-S^{\frac{1}{\tau}} \mu_{\max } \mathrm{M}$ \\
\hline
\end{tabular}

